\title{
Clinical characteristics of patients with chronic obstructive pulmonary disease with comorbid bronchiectasis: a systemic review and meta-analysis
}

This article was published in the following Dove Press journal:

International Journal of COPD

28 July 2015

Number of times this article has been viewed

\section{Yingmeng $\mathrm{Ni}$ \\ Guochao Shi \\ Youchao Yu \\ Jimin Hao \\ Tiantian Chen \\ Huihui Song}

Department of Pulmonary Medicine, Ruijin Hospital, Shanghai Jiao Tong University School of Medicine, Shanghai, People's Republic of China

Correspondence: Guochao Shi Department of Pulmonary Medicine, Ruijin Hospital, Shanghai Jiao Tong University School of Medicine, Shanghai 200025, People's Republic of China

Tel +86 I 3918462035

Emailshiguochao@hotmail.com
Background: In the 2014 Global initiative for chronic Obstructive Lung Disease guidelines, bronchiectasis was for the first time defined as a comorbidity of chronic obstructive pulmonary disease (COPD), and this change has been retained in the 2015 update, which emphasizes the influence of bronchiectasis in the natural history of COPD. The present meta-analysis was aimed at summarizing the impact of bronchiectasis on patients with COPD.

Methods: Databases including Embase, PubMed, and the Cochrane Central Register of Controlled Trials were searched comprehensively to identify all relevant human clinical studies published until August 2014. Bronchiectasis was confirmed either by computed tomography or high-resolution computed tomography. One or more clinicopathological or demographical characteristics, including age, sex, smoking history, daily sputum production, exacerbations, inflammatory biomarkers, lung function, and colonization by potentially pathogenic microorganisms (PPMs), were compared between COPD patients with and without bronchiectasis.

Results: Six observational studies with 881 patients were included in the meta-analysis. The mean prevalence of bronchiectasis in patients with COPD was $54.3 \%$, ranging from $25.6 \%$ to $69 \%$. Coexistence of bronchiectasis and COPD occurred more often in male patients with longer smoking history. Patients with COPD and comorbid bronchiectasis had greater daily sputum production, more frequent exacerbation, poorer lung function, higher level of inflammatory biomarkers, more chronic colonization by PPMs, and higher rate of Pseudomonas aeruginosa isolation.

Conclusion: In spite of the heterogeneity between included studies and detectable publication bias, this meta-analysis demonstrated the impact of bronchiectasis in patients with COPD in all directions, indicating that coexistence of bronchiectasis should be considered a pathological phenotype of COPD, which may have a predictive value.

Keywords: bronchiectasis, chronic obstructive pulmonary disease, phenotype, meta-analysis

\section{Introduction}

With the increased use of computed tomography (CT) in the assessment of chronic obstructive pulmonary disease (COPD), the presence of coexisting bronchiectasis is being identified more frequently. Several studies have revealed a high prevalence of bronchiectasis in patients with COPD, ranging from $20 \%$ to $69 \% .^{1-4}$ In the 2014 Global initiative for chronic Obstructive Lung Disease (GOLD) guidelines, bronchiectasis was for the first time defined as a comorbidity of COPD, and this change has been retained in the 2015 update, ${ }^{5}$ which emphasizes the influence of bronchiectasis in the natural history of COPD. ${ }^{6}$ 
There are evidences that bronchiectasis influences the clinical outcomes of COPD. Studies have shown that patients with COPD and comorbid bronchiectasis have higher risk of becoming chronic sputum producers, have more purulent sputum, have more airway or systemic inflammation, and have more exacerbations. ${ }^{1-3,7-10}$

The worse clinical outcomes in patients with COPD and comorbid bronchiectasis may be associated with chronic colonization of potentially pathogenic microorganisms (PPMs). In earlier studies, PPMs were isolated more frequently from the sputum of patients with COPD and comorbid bronchiectasis during the stable phase, ${ }^{7,9}$ as well as during acute exacerbation. ${ }^{3,10}$

However, in previous studies, controversial results on clinical outcomes, such as lung function and exacerbations, have been reported with relatively small patient populations (44-118 patients). ${ }^{1,4,7,9,10,11-17}$ Hence, the present meta-analysis was aimed at summarizing the reports on the comorbidity of bronchiectasis and COPD and further clarifying the impact of bronchiectasis on patients with COPD.

\section{Methods}

The recommendations of the Preferred Reporting Items for Systematic Reviews and Meta-Analysis (PRISMA) were followed for conducting and the reporting of this review. ${ }^{18}$ All analyses were performed on data of previously published studies, and thus no ethical approval and patient consent were required.

\section{Search strategy for identification of studies}

A literature search was performed to identify the clinical studies that addressed the impact of bronchiectasis in patients with COPD. Databases including Embase, PubMed, and the Cochrane Central Register of Controlled Trials were searched comprehensively to identify all relevant human clinical studies published until August 2014. The search strategy used was as follows: (["pulmonary disease, chronic obstructive"] OR ["pulmonary" AND "disease" AND "chronic" AND "obstructive"] OR ["chronic obstructive pulmonary disease"] OR ["COPD” AND ("bronchiectasis") AND English [language]).

\section{Study selection}

Two investigators independently obtained the full texts of potentially eligible manuscripts based on their titles and abstracts. To avoid the double counting of patients recruited in more than one study, the authors were contacted for inquiry when necessary.

\section{Inclusion and exclusion criteria}

Manuscripts were included in this meta-analysis if they met the following criteria: 1) According to the GOLD guidelines, COPD was defined as follows: postbronchodilator ratio of forced expiratory volume in 1 second/forced vital capacity ( $\mathrm{FEV}_{1} / \mathrm{FVC}$ ) of $<70 \%$ in a patient with a smoking history of $>10$ pack-years; ${ }^{6}$ ) bronchiectasis was confirmed either by $\mathrm{CT}$ or high-resolution CT (HRCT), and patients with known cause of bronchiectasis were excluded; and 3) one or more clinicopathological or demographical characteristics, including age, sex, smoking history, daily sputum production, exacerbations, inflammatory biomarkers, lung function, and colonization by PPMs, were compared between COPD patients with and without bronchiectasis. Conference abstracts, case reports, editorials, and narrative reviews were excluded in this meta-analysis.

\section{Data extraction}

Two investigators independently extracted the following data from the selected studies: the first author's name and year of publication; patients' age, sex, smoking history, daily sputum production, and exacerbations in previous year; albumin and C-reactive protein (CRP) levels; postbronchodilator $\mathrm{FEV}_{1} \%$ predicted and postbronchodilator ratio of $\mathrm{FEV}_{1} /$ FVC; and rate of PPM colonization and rate of Pseudomonas aeruginosa isolation. The quality of included studies was evaluated according to the Agency for Healthcare Research and Quality standard. ${ }^{19}$

\section{Statistical analysis}

The meta-analysis was conducted using the open source Review Manager (RevMan) software (Version 5.3.4, available at the Web site http://ims.cochrane.org/revman/download). Irrespective of the presence of heterogeneity between studies, the random-effects model was used to combine individual effect-size estimates. The relationship between clinicopathological or demographical profiles, including sex, daily sputum production, rate of PPM colonization, and rate of $P$. aeruginosa isolation, and coexistence of bronchiectasis in COPD were assessed using the inverse variance method, and effect estimates were assessed as odds ratio (OR $)^{20}$ and $95 \%$ confidence interval $(95 \% \mathrm{CI})$. Differences in age, smoking history, exacerbation in previous year, levels of albumin and $\mathrm{CRP}$, postbronchodilator $\mathrm{FEV}_{1} \%$ predicted, and postbronchodilator ratio of $\mathrm{FEV}_{1} / \mathrm{FVC}$ between $\mathrm{COPD}$ patients with and without bronchiectasis were estimated using the inverse variance method, and contrasts were expressed in the form of weighted mean difference (WMD) and 95\% CI. For those 
manuscripts without standard deviation (SD), an average SD was estimated using the methods described by Hozo et al. ${ }^{21}$

To test the interstudy heterogeneity, the chi-square value was calculated for the assumption of homogeneity. The fixed-effects model was chosen when there was no heterogeneity, while the random-effects model was chosen when there was heterogeneity. Publication bias was assessed using funnel plots.

\section{Results}

\section{Search results}

Through database search, 742 potentially relevant articles were identified. After reviewing the abstracts and full texts, 12 manuscripts about bronchiectasis in patients with COPD were found. . 1,6, $, 11-17,21,22$ Of those, six studies met the inclusion criteria, which included patients with COPD and comorbid bronchiectasis $(n=550)$ and patients with COPD and without comorbid bronchiectasis $(n=331)^{1,4,7,11-13}$ The flow diagram of the database search is represented in Figure 1.

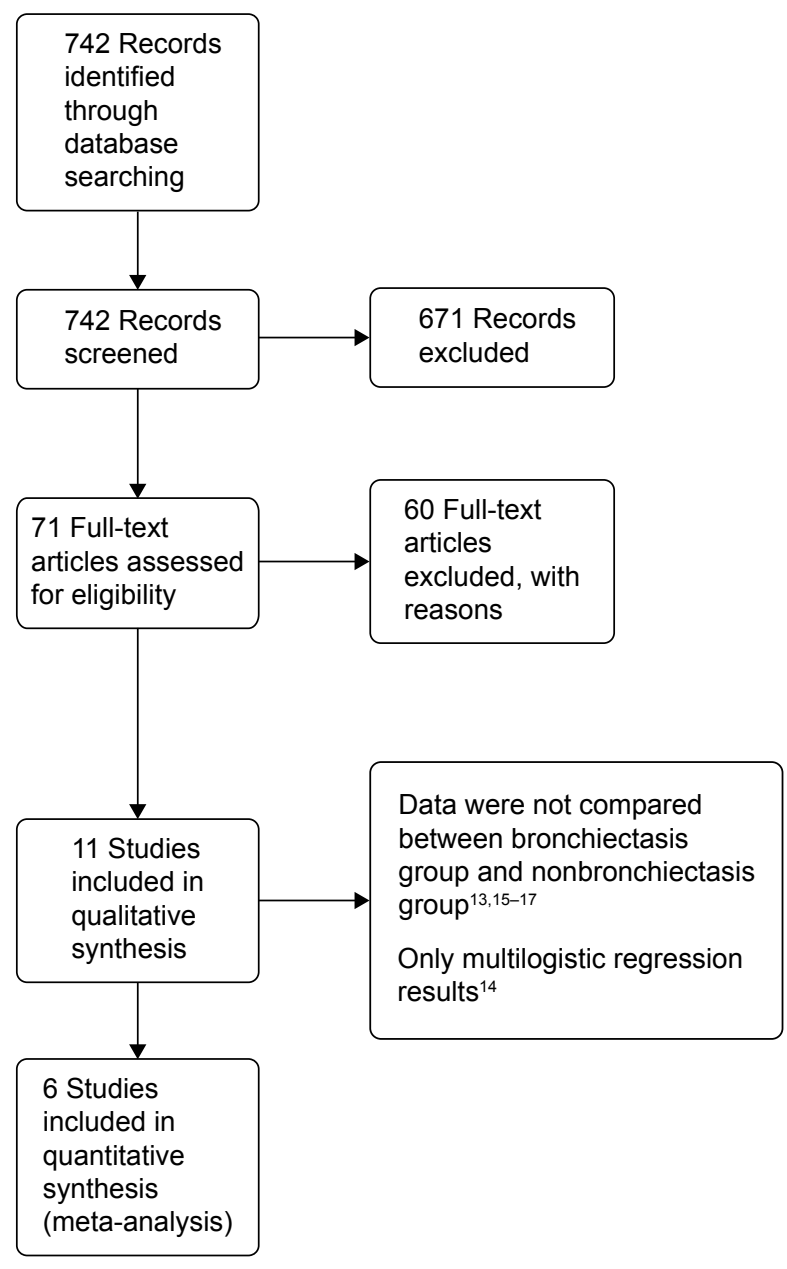

Figure I Flow diagram of search strategy and study selection.
The mean prevalence of bronchiectasis in patients with COPD was 54.3\% (range: $25.6 \%-69 \%$ ). HRCT was used to diagnose bronchiectasis in all studies, except in the study by Gatheral et $\mathrm{al}^{4}$ wherein a part of patients were diagnosed with bronchiectasis using CT images of 2-3 mm slice thickness (134 patients out of 406 patients, $33 \%$ ) or 5-7 mm slice thickness (106 patients out of 406 patients, 26\%). In their study, the comparative analysis of results of CT images with different slice thicknesses showed no underdetection of abnormalities in thicker CT sections; therefore, their analysis was performed irrespective of the used CT slice thickness. The characteristics of all included studies are summarized in Tables 1 and 2. The quality evaluation of included studies is shown in Table 3.

\section{Demographic characteristics}

Patients with COPD and comorbid bronchiectasis were older than those without bronchiectasis (WMD: 1.8 years; 95\% CI: 0.05 to 3.55 ; $P=0.04$; Figure 2 ); although there was a publication bias detected in the funnel plot (Figure S1). Meta-analysis of five studies providing sex information showed a higher prevalence of coexistence of bronchiectasis in male COPD patients (OR: 1.62; 95\% CI: 1.15 to 2.28; $P=0.006$; Figure 3 ). Smoking history in COPD patients with bronchiectasis was also significantly longer than those without bronchiectasis (WMD: 4.63 pack-years; 95\% CI: 1.61 to 7.65 ; $P=0.003$; Figure 4). Funnel plots of these two parameters showed no observable publication bias (Figures S2 and S3).

\section{Clinical features}

Figures 5 and 6 show that patients with COPD and comorbid bronchiectasis exhibited more daily sputum production (OR: 2.30; 95\% CI: 1.66 to 3.19; $P<0.00001$; Figure 5) and more exacerbations (WMD: 1.54 times in the previous year; 95\% CI: 0.56 to $2.53 ; P=0.002$; Figure 6 ) than COPD patients without bronchiectasis. Publication bias was observed in exacerbation, but not in daily sputum production (Figures S4 and S5).

\section{Lung function}

COPD patients with bronchiectasis showed a lower $\mathrm{FEV}_{1}$ / FVC ratio (WMD: $-8.05 \%$; 95\% CI: -10.65 to -5.45 ; $P<0.00001$; Figure 7), and airway obstruction was more severe with a lower postbronchodilator $\mathrm{FEV}_{1} \%$ predicted in this group of patients (WMD: -11.06 ; 95\% CI: -18.27 to $-3.85 ; P=0.003$; Figure 8 ). However, funnel plots showed a significant publication bias in the $\mathrm{FEV}_{1} / \mathrm{FVC}$ ratio and postbronchodilator $\mathrm{FEV}_{1} \%$ predicted (Figures S6 and S7). 
Table I Characteristics of included studies

\begin{tabular}{|c|c|c|c|c|c|}
\hline $\begin{array}{l}\text { Study } \\
\text { number }\end{array}$ & Authors & $\begin{array}{l}\text { Publication } \\
\text { year }\end{array}$ & $\begin{array}{l}\text { Time frame of } \\
\text { patients' recruitment }\end{array}$ & Severity of COPD & Parameters under study \\
\hline $\mathrm{I}$ & $\begin{array}{l}\text { Fujimoto } \\
\text { et al" }\end{array}$ & 2006 & $\begin{array}{l}\text { September } 2002 \text { to } \\
\text { September } 2004\end{array}$ & Moderate, severe & $\begin{array}{l}\text { Sex, age, smoking history, onset of symptoms, } \mathrm{BMI} \text {, } \\
\alpha_{1} \text {-antitrypsin, eosinophil counts, daily sputum production, } \\
\text { exacerbation rate, hospitalization rate, post-BD FEV } / \mathrm{FVC} \text {, } \\
\text { post-BD FEV }, \mathrm{TLC}, \mathrm{PaO}_{2}, \mathrm{PaCO}_{2} \text {, response to } \beta_{2} \text {-agonist }\end{array}$ \\
\hline 2 & $\begin{array}{l}\text { Martínez- } \\
\text { García et al }{ }^{7}\end{array}$ & 2011 & $\begin{array}{l}\text { January } 2004 \text { to } \\
\text { December } 2006\end{array}$ & Moderate, severe & $\begin{array}{l}\text { Sex, age, smoking history, onset of symptoms, daily } \\
\text { sputum production, daily treatments, dyspnea MRC, } \\
\text { exacerbation in previous year, acute antibiotic treatments, } \\
\text { acute oral steroid treatments, fibrinogen, albumin, CRP, } \\
\alpha_{1} \text {-antitrypsin, post-BD FEV,/FVC, post-BD FEV, PPM } \\
\text { colonization, Pseudomonas aeruginosa isolates, Haemophilus } \\
\text { influenzae isolates }\end{array}$ \\
\hline 3 & Bafadhel et al' & 2011 & Not mentioned & Not mentioned & $\begin{array}{l}\text { Sex, age, smoking history, daily sputum production, } \\
\text { sputum total cell count, exacerbation in previous year, } \\
\text { BMI, SGRQ score, CRQ score, VAS score, ICS dosage, } \\
\text { post-BD FEV,/FVC, post-BD FEV }\end{array}$ \\
\hline 4 & $\begin{array}{l}\text { Martínez- } \\
\text { García et al }\end{array}$ & 2013 & $\begin{array}{l}\text { January } 2004 \text { to } \\
\text { February } 2007\end{array}$ & Moderate, severe & $\begin{array}{l}\text { Sex, age, smoking history, onset of symptoms, daily } \\
\text { sputum production, daily treatments, BMI, dyspnea MRC, } \\
\text { exacerbation in previous year, acute antibiotic treatments, } \\
\text { acute oral steroid treatments, all-cause mortality, albumin, } \\
\text { CRP, } \alpha_{1} \text {-antitrypsin, post-BD FEV } / \text { FVC, post-BD FEV }, \\
\text { post-BD FVC, PPM colonization, Pseudomonas aeruginosa } \\
\text { isolates, Haemophilus influenzae isolates }\end{array}$ \\
\hline 5 & Tulek et al ${ }^{12}$ & 2013 & $\begin{array}{l}\text { January } 2010 \text { to } \\
\text { May } 2012\end{array}$ & $\begin{array}{l}\text { Mild, moderate, } \\
\text { severe, very severe }\end{array}$ & $\begin{array}{l}\text { Age, smoking history, onset of symptoms, daily sputum } \\
\text { production, exacerbation in previous year, albumin, CRP, } \\
\text { ESR, post-BD FEV } / \text { FVC, post-BD FE, } V_{1} \text {, post-BD FVC }\end{array}$ \\
\hline 6 & Gatheral et $\mathrm{al}^{4}$ & 2014 & $\begin{array}{l}\text { January } 1998 \text { to } \\
\text { September } 2008\end{array}$ & Not mentioned & $\begin{array}{l}\text { Sex, age, onset of symptoms, daily sputum production, } \\
\text { post-BD FEV } / \text { FVC, post-BD FEV }, \text { PPM colonization, } \\
\text { Pseudomonas aeruginosa isolates, Haemophilus influenzae } \\
\text { isolates, respiratory admissions per year, nonrespiratory } \\
\text { admissions per year, age at death }\end{array}$ \\
\hline
\end{tabular}

Abbreviations: BMI, body mass index; CRP, C-reactive protein; COPD, chronic obstructive pulmonary disease; CRQ, Chronic Respiratory Disease Interviewer-Administered Questionnaire; ESR, erythrocyte sedimentation rate; ICS, inhaled corticosteroid; MRC, Medical Research Council; post-BD FEV/FVC, ratio of postbronchodilation forced expiratory volume in I second and forced vital capacity; post-BD FEV , postbronchodilation forced expiratory volume in I second; PPM, potentially pathogenic microorganisms; SGRQ, Saint George's Research Questionnaire score; TLC, total lung capacity; VAS, visual analog scale.

\section{Inflammatory biomarkers}

CRP level was higher in COPD patients with bronchiectasis compared with those without bronchiectasis (WMD: 6.11; 95\% CI: 0.26 to 11.95 ; $P=0.04$; Figure 9). However, a significant publication bias was detectable by funnel plots (Figure S8). Albumin level was lower in COPD patients with bronchiectasis compared with those without the same (WMD: $-0.14 ; 95 \%$ CI: -0.23 to $-0.06 ; P=0.001$; Figure 10 ), and no publication bias was observed (Figure $S 9$ ).

\section{Microbiological study}

COPD patients with bronchiectasis were at increased risk of having chronic PPM colonization, compared with those without bronchiectasis (OR: 7.33; 95\% CI: 4.61 to 11.67 ; $P<0.00001$; Figure 11). Moreover, P. aeruginosa was more frequently isolated in COPD patients with bronchiectasis
(OR: 3.5; 95\% CI: 1.89 to $6.47 ; P<0.0001$; Figure 12 ). Funnel plots showed no observable publication bias for these two variables (Figures S10 and S11).

\section{Sensitivity analysis}

In the study by Gatheral et $\mathrm{al}^{4} \mathrm{HRCT}$ was not performed for each enrolled patient, which might lead to underestimation of the prevalence of bronchiectasis, although the authors had confirmed that there was no underdetection of bronchiectasis in their study. As the study by Gatheral et $\mathrm{al}^{4}$ had a significant weightage in meta-analysis, a sensitivity analysis was carried out for five studies excluding the study by Gatheral et al. ${ }^{4}$ The sensitivity analysis showed that the meta-analysis results on age, sex, daily sputum production, lung function, and PPM isolation did not change after excluding the study by Gatheral et al (Figures S12-S18). 
Table 2 Radiological characteristics of COPD patients in the included studies

\begin{tabular}{|c|c|c|c|}
\hline Study number & CT slice thickness & $\begin{array}{l}\mathbf{N} \text { (with/without } \\
\text { bronchiectasis) }\end{array}$ & Diagnostic criteria of bronchiectasis \\
\hline I & $\begin{array}{l}\text { I mm collimation at } \\
10 \mathrm{~mm} \text { intervals }\end{array}$ & $44 / 39$ & Method of Goddard et $\mathrm{a}^{23}$ \\
\hline 2 & $\begin{array}{l}\text { I mm collimation at } \\
10 \mathrm{~mm} \text { intervals }\end{array}$ & $53 / 39$ & $\begin{array}{l}\text { I) Lack of tapering of bronchi, 2) dilation of } \\
\text { bronchi when the internal diameter was larger } \\
\text { than that of the adjacent pulmonary artery, } \\
\text { 3) visualization of the peripheral bronchi } \\
\text { within I cm of the costal pleural surface or } \\
\text { adjacent mediastinal pleural surface }\end{array}$ \\
\hline 3 & $\begin{array}{l}\text { I mm collimation at } \\
10 \mathrm{~mm} \text { intervals }\end{array}$ & $33 / 13$ & $\begin{array}{l}\text { I) Lack of tapering of bronchi, 2) dilation of } \\
\text { bronchi when the internal diameter was larger } \\
\text { than that of the adjacent pulmonary artery, } \\
\text { 3) visualization of the peripheral bronchi } \\
\text { within I cm of the costal pleural surface or } \\
\text { adjacent mediastinal pleural surface }\end{array}$ \\
\hline 4 & $\begin{array}{l}\text { I mm collimation at } \\
10 \mathrm{~mm} \text { intervals }\end{array}$ & $115 / 86$ & $\begin{array}{l}\text { I) Lack of tapering of bronchi, 2) dilation of } \\
\text { bronchi when the internal diameter was larger } \\
\text { than that of the adjacent pulmonary artery, } \\
\text { 3) visualization of the peripheral bronchi } \\
\text { within I cm of the costal pleural surface or } \\
\text { adjacent mediastinal pleural surface }\end{array}$ \\
\hline 5 & $\begin{array}{l}\text { I mm collimation at } \\
10 \mathrm{~mm} \text { intervals }\end{array}$ & $27 / 26$ & Bhalla scoring system ${ }^{24}$ \\
\hline 6 & $\begin{array}{l}\text { I } \mathrm{mm} \text { or } 2.5 \mathrm{~mm} \text { or } 5 \mathrm{~mm} \\
\text { or } 7 \mathrm{~mm} \text { collimation at } \\
10 \mathrm{~mm} \text { intervals }\end{array}$ & $278 / 128$ & $\begin{array}{l}\text { I) Lack of tapering of bronchi, 2) dilation of } \\
\text { bronchi when the internal diameter was larger } \\
\text { than that of the adjacent pulmonary artery, } \\
\text { 3) visualization of the peripheral bronchi } \\
\text { within I cm of the costal pleural surface or } \\
\text { adjacent mediastinal pleural surface }\end{array}$ \\
\hline
\end{tabular}

Note: Refer Table I for details of studies.

Abbreviations: COPD, chronic obstructive pulmonary disease; CT, computed tomography.

Table 3 Evaluation of quality of included studies

\begin{tabular}{|c|c|c|c|c|c|c|}
\hline \multirow{2}{*}{$\begin{array}{l}\text { Agency for Healthcare Research and Quality standard } \\
\text { for cross-sectional study quality }\end{array}$} & \multicolumn{6}{|c|}{ Study number } \\
\hline & $\mathbf{I}$ & 2 & 3 & 4 & 5 & 6 \\
\hline Define the source of information & Yes & Yes & Yes & Yes & Yes & Yes \\
\hline $\begin{array}{l}\text { List inclusion and exclusion criteria for exposed and unexposed } \\
\text { subjects (cases and controls) or refer to previous publications }\end{array}$ & Yes & Yes & Yes & Yes & Yes & Yes \\
\hline Indicate time period used for identifying patients & Yes & Yes & No & Yes & Yes & Yes \\
\hline $\begin{array}{l}\text { Indicate whether or not subjects were consecutive if not } \\
\text { population based }\end{array}$ & Yes & Yes & Yes & Yes & Yes & Yes \\
\hline $\begin{array}{l}\text { Indicate if evaluators of subjective components of study were } \\
\text { masked to other aspects of the status of the participants }\end{array}$ & Yes & Yes & No & No & Yes & No \\
\hline $\begin{array}{l}\text { Describe any assessments undertaken for quality assurance } \\
\text { purposes }\end{array}$ & No & Yes & No & No & Yes & Yes \\
\hline Explain any patient exclusions from analysis & Yes & Yes & Yes & Yes & Yes & Yes \\
\hline Describe how confounding was assessed and/or controlled & Unclear & Yes & Unclear & Yes & Yes & Unclear \\
\hline $\begin{array}{l}\text { If applicable, explain how missing data were handled in the } \\
\text { analysis }\end{array}$ & - & - & - & Yes & - & - \\
\hline $\begin{array}{l}\text { Summarize patient response rates and completeness of data } \\
\text { collection }\end{array}$ & Yes & Yes & Yes & Yes & Yes & Yes \\
\hline $\begin{array}{l}\text { Clarify what follow-up, if any, was expected and the percentage } \\
\text { of patients for which incomplete data or follow-up was obtained }\end{array}$ & Yes & - & - & Yes & - & Yes \\
\hline
\end{tabular}

Note: Refer Table I for details of studies. 


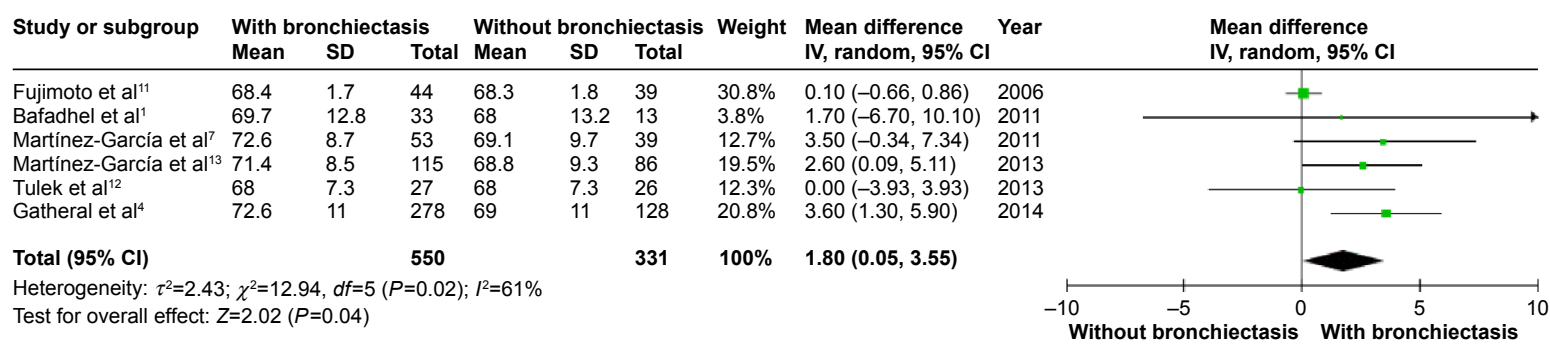

Figure 2 Forest plot of mean difference of age in COPD patients with and without bronchiectasis.

Abbreviations: $\mathrm{Cl}$, confidence interval; SD, standard deviation; COPD, chronic obstructive pulmonary disease; IV, inverse variance.

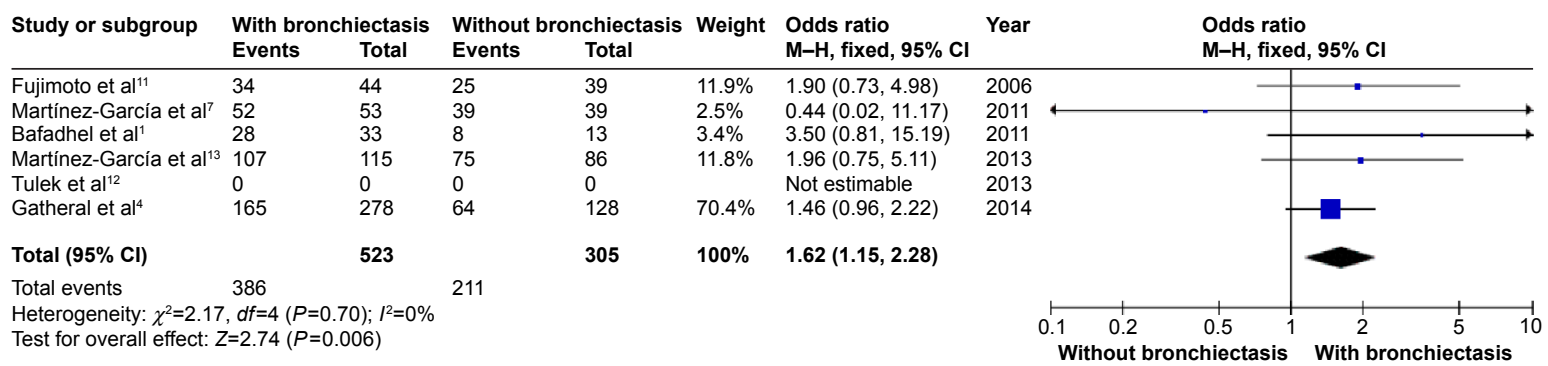

Figure 3 Forest plot of odds ratios of sex in COPD patients with and without bronchiectasis.

Abbreviations: $\mathrm{Cl}$, confidence interval; COPD, chronic obstructive pulmonary disease; $\mathrm{M}-\mathrm{H}$, Mantel-Haenszel method.

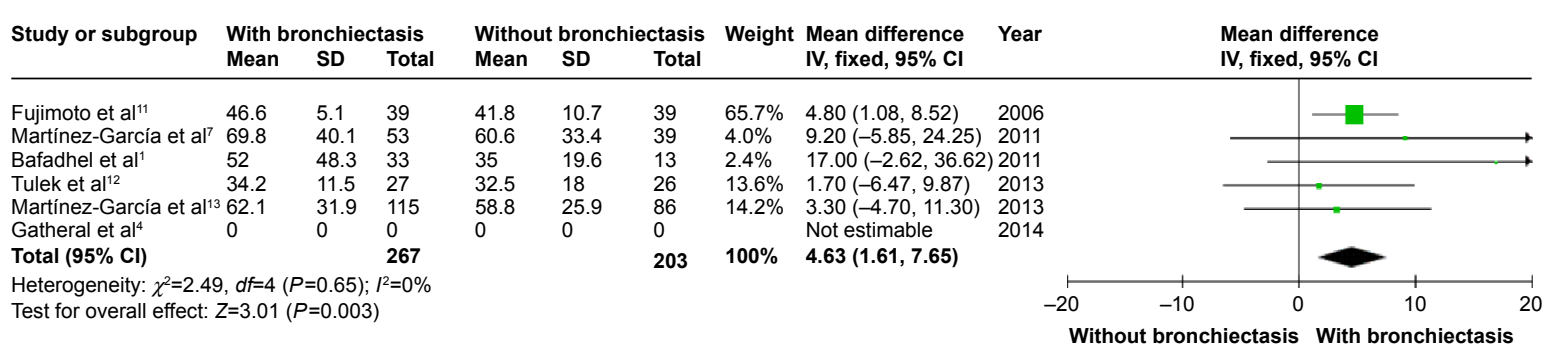

Figure 4 Forest plot of mean difference of smoking history (pack-years) in COPD patients with and without bronchiectasis.

Abbreviations: $\mathrm{Cl}$, confidence interval; COPD, chronic obstructive pulmonary disease; IV, inverse variance; SD, standard deviation.

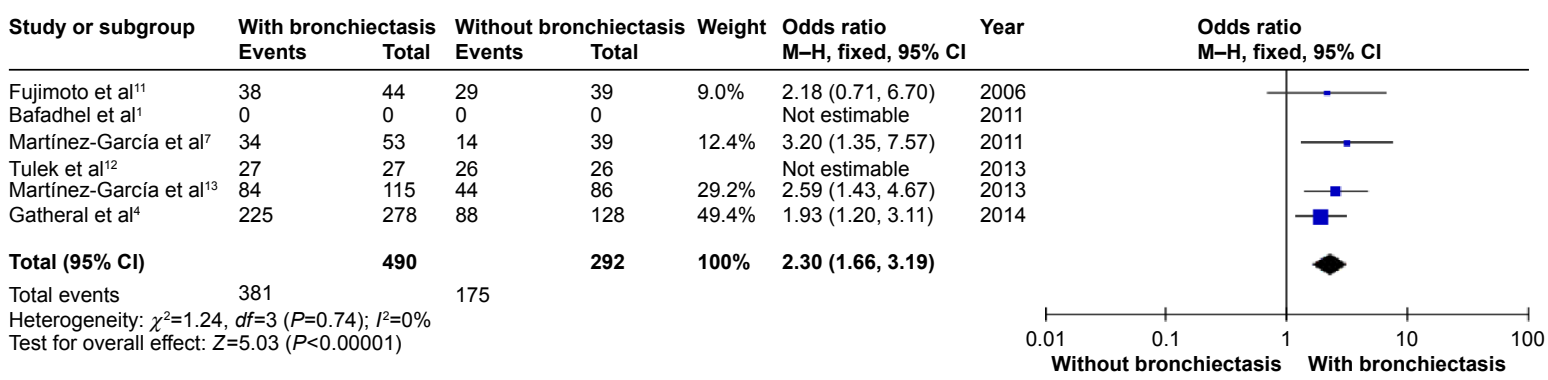

Figure 5 Forest plot of odds ratios of daily sputum production in COPD patients with and without bronchiectasis.

Abbreviations: $\mathrm{Cl}$, confidence interval; COPD, chronic obstructive pulmonary disease; $\mathrm{M}-\mathrm{H}$, Mantel-Haenszel method. 


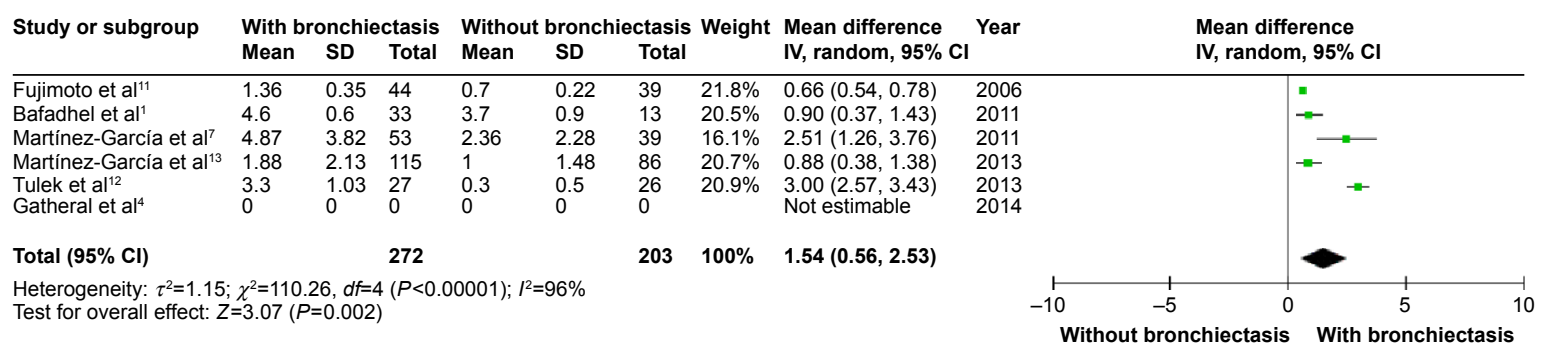

Figure 6 Forest plot of mean difference in exacerbations in COPD patients with and without bronchiectasis.

Abbreviations: $\mathrm{Cl}$, confidence interval; COPD, chronic obstructive pulmonary disease; IV, inverse variance; SD, standard deviation.

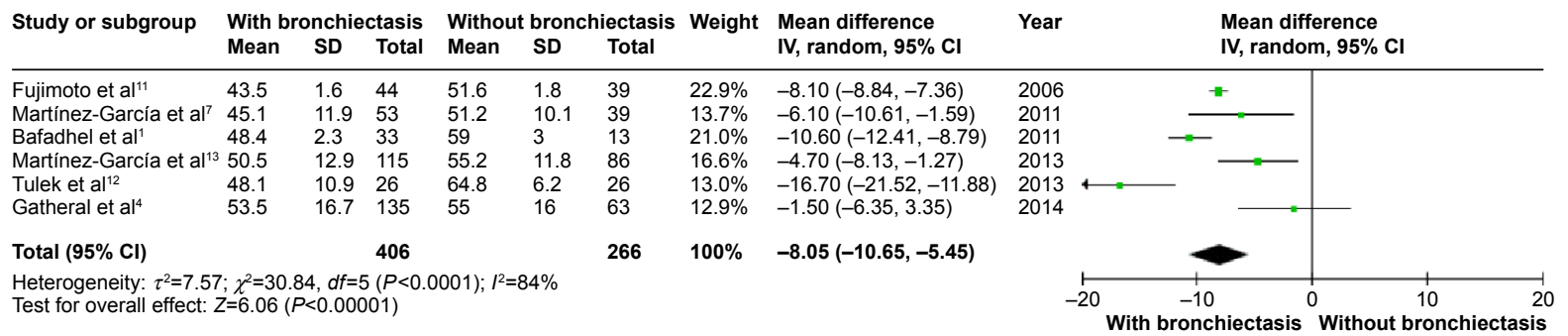

Figure 7 Forest plot of mean difference of postbronchodilator $\mathrm{FEV} / \mathrm{FVC} \%$ in COPD patients with and without bronchiectasis.

Abbreviations: $\mathrm{Cl}$, confidence interval; COPD, chronic obstructive pulmonary disease; FEV , forced expiratory volume in I second; FVC, forced vital capacity; IV, inverse variance; SD, standard deviation.

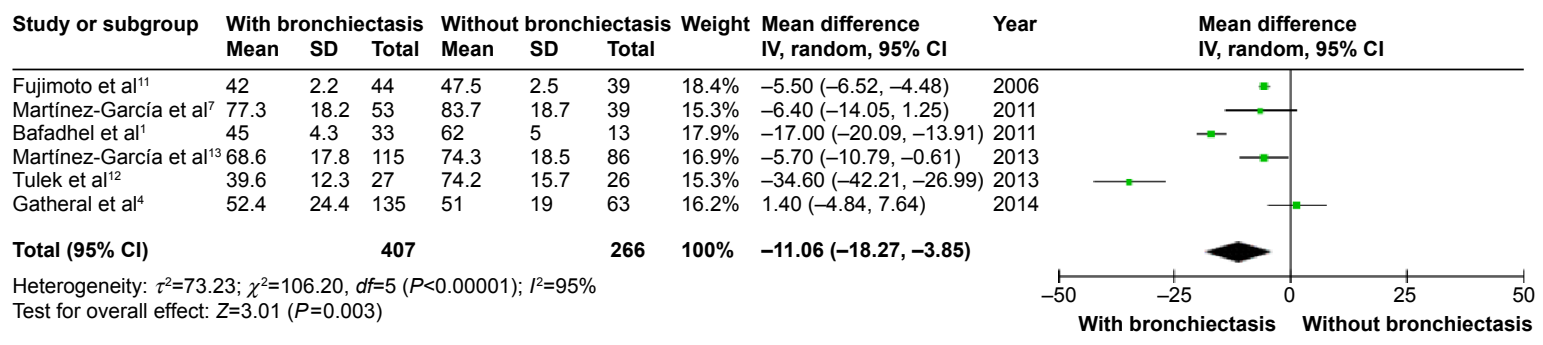

Figure 8 Forest plot of mean difference of postbronchodilator $\mathrm{FEV}_{1} \%$ predicted in COPD patients with and without bronchiectasis.

Abbreviations: $\mathrm{Cl}$, confidence interval; COPD, chronic obstructive pulmonary disease; $\mathrm{FEV} \%$, forced expiratory volume in I second; IV, inverse variance; SD, standard deviation.

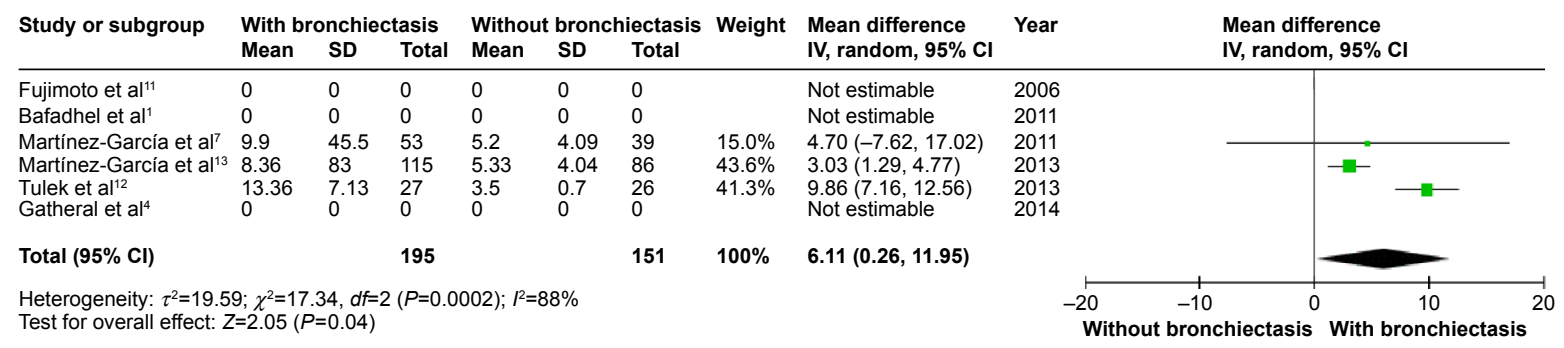

Figure 9 Forest plot of mean difference of CRP in COPD patients with and without bronchiectasis.

Abbreviations: $\mathrm{Cl}$, confidence interval; COPD, chronic obstructive pulmonary disease; CRP, C-reactive protein; IV, inverse variance; SD, standard deviation. 


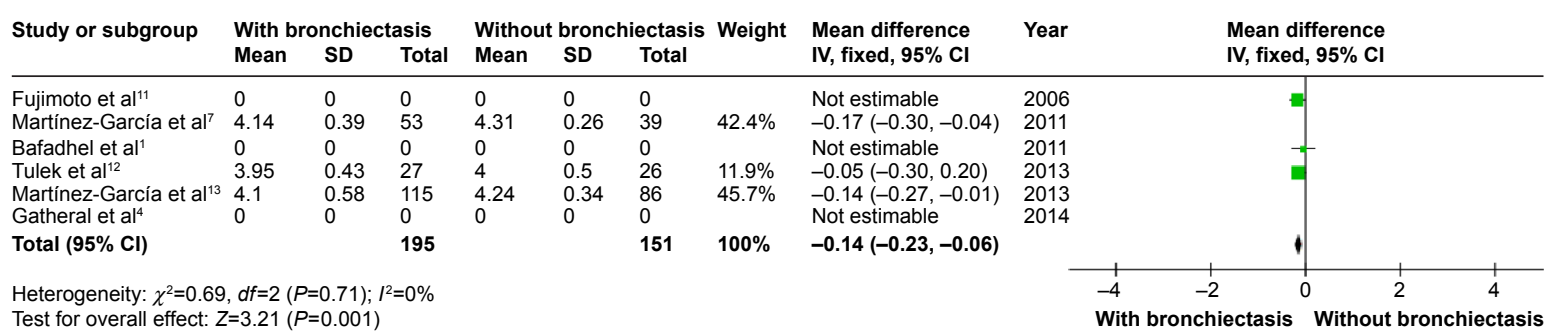

Figure 10 Forest plot of mean difference of albumin in COPD patients with and without bronchiectasis.

Abbreviations: $\mathrm{Cl}$, confidence interval; COPD, chronic obstructive pulmonary disease; IV, inverse variance; SD, standard deviation.

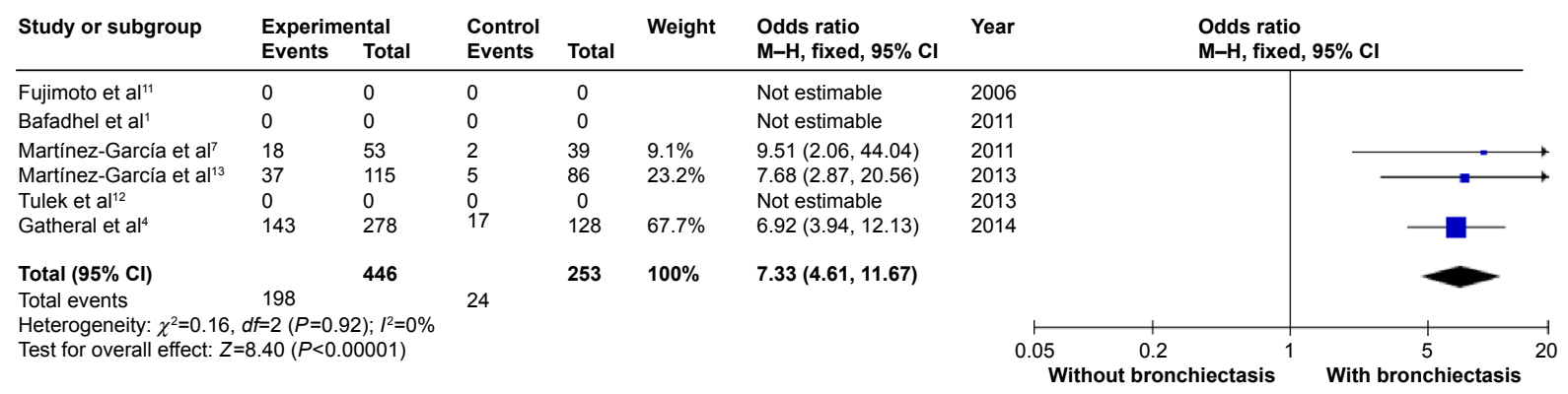

Figure I I Forest plot of odds ratios of chronic PPM colonization in COPD patients with and without bronchiectasis.

Abbreviations: $\mathrm{Cl}$, confidence interval; COPD, chronic obstructive pulmonary disease; $\mathrm{M}-\mathrm{H}$, Mantel-Haenszel method; PPM, potentially pathogenic microorganisms.

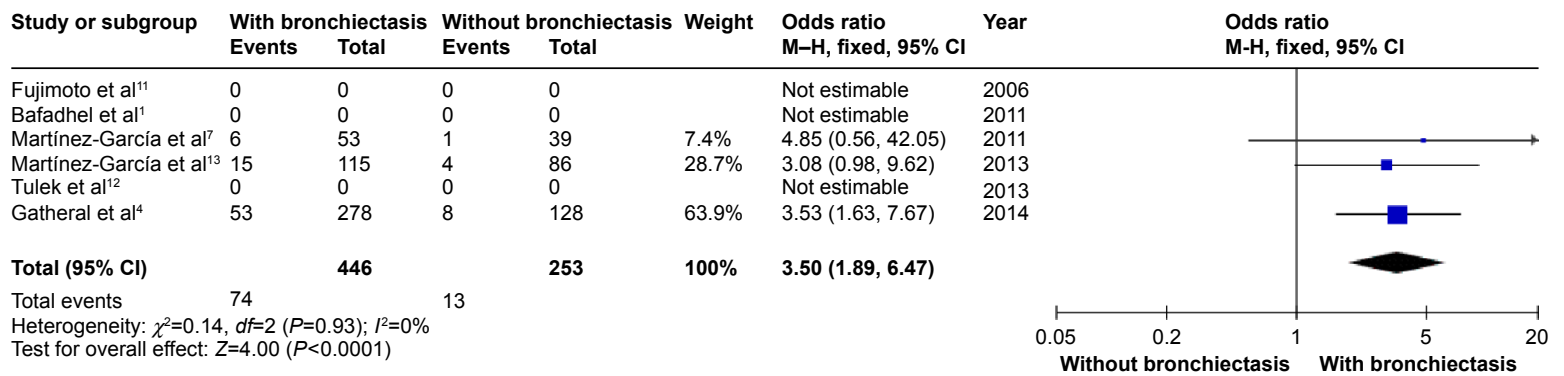

Figure 12 Forest plot of odds ratios of Pseudomonas aeruginosa isolation in COPD patients with and without bronchiectasis. Abbreviations: $\mathrm{Cl}$, confidence interval; COPD, chronic obstructive pulmonary disease; $\mathrm{M}-\mathrm{H}$, Mantel-Haenszel method.

\section{Discussion}

COPD is an airway disease with a variable clinical course that is not well predicted based solely on the usual objective tests such as spirometry. ${ }^{5}$ Research has been conducted to identify specific COPD phenotypes. An emerging area of COPD phenotype research is the use of radiologic imaging to categorize patients into different phenotypes based on the degree of emphysema and bronchial wall thickening, a prominent imaging feature of bronchiectasis., 11,25-27 The "emphysema hyperinflation phenotype" was relatively well established in previous studies, defining patients with COPD who present with dyspnea and intolerance to exercise as the predominating symptoms, accompanied by signs of hyperinflation. ${ }^{28}$ However, the role of bronchiectasis in COPD remains unclear.
In this meta-analysis, we tried to clarify the impact of coexistence of bronchiectasis in patients with COPD.

The present study as well as previous studies showed a high rate of coexistence of bronchiectasis and COPD, which could be explained by overlapped pathological mechanisms. In both bronchiectasis and COPD, neutrophils and $\mathrm{T}$ lymphocytes are the predominant inflammatory cells; $;{ }^{29,30}$ the neutrophils release proteases, which cause pulmonary structure damage, whereas $\mathrm{T}$ lymphocytes lead to enlargement of peribronchial lymph nodes and chronic airway inflammation, resulting in airflow obstruction. ${ }^{31,32}$ In contrast, only $4 \%$ of COPD patients in the ECLIPSE cohort had bronchiectasis, which may be secondary to the fact that patients with other pulmonary conditions were excluded..$^{33}$ 
In the present study, it was shown that coexistence of bronchiectasis and COPD happened more often in elder male patients with longer smoking history. This finding is consistent with the consideration that tobacco exposure is one of the most important causes of chronic bronchiolitis, the latter being considered to be the fundamental pathogenic mechanism of bronchiectasis. ${ }^{34-36}$

The most significant results of the meta-analysis were the high OR of chronic PPM colonization and $P$. aeruginosa isolation ( 7.33 and 3.59, respectively). However, it should be noted that "chronic colonization" was replaced by "persistent infection" in the study by Gatheral et $\mathrm{al}^{4}$ this replacement could lead to the increased rate of chronic PPM colonization in the present meta-analysis. However, sensitivity analysis showed no difference after excluding the study by Gatheral et al. ${ }^{4}$ Previous studies have not confirmed the significant association between $P$. aeruginosa and bronchiectasis in patients with COPD. ${ }^{37}$ With this meta-analysis of patients with COPD ( $\mathrm{n}=742$ ), the association of chronic PPM colonization, as well as $P$. aeruginosa isolation, with bronchiectasis in COPD patients has been definitely determined. According to the hypothesis of Cole, ${ }^{38}$ it is possible that the presence of PPM and concomitant proteolytic products is responsible for triggering the mechanism that generates bronchiectasis, along with the chronic inflammation of the bronchial mucosa secondary to this phenomenon in some patients with COPD. Moreover, $P$. aeruginosa, one of the most important PPMs, has been isolated from $3 \%$ to $20 \%$ of patients with COPD and, more frequently, from patients with severe disease and during exacerbations. ${ }^{39-42} P$. aeruginosa isolation has been associated with higher 3-year mortality, more hospital admissions in the previous year, higher BODE index scores, and more systemic steroid treatment. ${ }^{9,43}$ In the present meta-analysis, two of the included studies provided information about treatment during exacerbation, which indicated that patients with COPD needed more acute oral steroid treatments along with acute antibiotic treatments. ${ }^{7}{ }^{13}$ Unfortunately, data were not enough to carry out a meta-analysis about the exacerbation treatments.

Permanent dilatation of the airways and impairment of mucociliary clearance may result in bacterial colonization in patients with bronchiectasis. Chronic airway infection, in turn, triggers an intense inflammatory response. ${ }^{29}$ Higher levels of sputum interleukin (IL)-6 and IL-8 were associated with coexistence of bronchiectasis in COPD. ${ }^{9}$ Due to the lack of enough studies, meta-analysis could not be performed on airway inflammatory cytokines. Thus, we tried to carry out the meta-analysis of some systemic biomarkers. The results showed a lower albumin level and a higher CRP level in patients with COPD and comorbid bronchiectasis, indicating a higher level of acute phase protein and anti-acute phase protein.

Bronchiectasis, as a result of the interaction of chronic PPM colonization and systemic inflammation, leads to distinctive clinical features, including more sputum production, frequent exacerbations, and more severe airway obstruction, as indicated in the present meta-analysis. As Martínez-García et al ${ }^{13}$ mentioned in their study, the presence of bronchiectasis in patients with COPD has a greater correlation with the parameters of patients with COPD with chronic bronchitis phenotype (thicker bronchial wall, greater daily sputum production, and a high number of exacerbations) than those with the emphysematous phenotype.

All the above-mentioned factors may lead to an elevated mortality in patients with COPD and comorbid bronchiectasis. Regrettably, only a few studies described the mortality data, and they were not enough to conduct a metaanalysis. The study of Martínez-García et al ${ }^{13}$ showed a higher mortality in patients with COPD and comorbid bronchiectasis $(n=201)$, with an adjusted hazard ratio of 1.15 . The study of Goeminne et a ${ }^{15}$ also showed a higher mortality in patients with bronchiectasis and comorbid COPD.

Recently, Hurst et $\mathrm{a}^{44}$ mentioned a new concept named COPD-bronchiectasis overlap syndrome in their review article. Considering the high prevalence of coexistence of bronchiectasis with COPD, as well as its poorer prognosis, the authors suggested that anatomical airway abnormalities of bronchiectasis in patients with COPD are best considered a phenotype of the COPD disease spectrum, and when managed in these patients, some treatments for bronchiectasis exacerbation, such as inhaled antibiotics including antipseudomonal agents, should be considered, but with a shorter course.

There are some limitations in our meta-analysis. First, there were significant biases for several outcomes, including age, exacerbation, lung function, and CRP level, as shown in funnel plots. This may be related to the publication bias and the small number of included studies. The limitation of search language and outcome bias may also play a role in these biases. Second, there were detectable interstudy heterogeneities in the meta-analysis, which were difficult to avoid as the number of included studies was too small. Among the six included studies, CT was used instead of HRCT in one of the studies to assess the patients. Although there was no underdetection of bronchiectasis, as the authors declared in their study, HRCT still showed a higher accuracy 
in diagnosing minor and mild bronchiectasis. ${ }^{45}$ Alternatively, different diagnosis criteria between studies may influence the results as well. Third, due to lack of data, meta-analyses of quality of life, treatment, sputum characteristics, blood gas parameters, and mortality were not performed.

\section{Conclusion}

Although with some limitations, this meta-analysis highlighted the impact of bronchiectasis in patients with COPD in all directions. Coexistence of bronchiectasis should be considered a pathological phenotype of COPD, which may have a predictive value.

\section{Acknowledgment}

We thank Professor Robert A Stockley for providing full text information.

\section{Disclosure}

The authors report no conflicts of interest in this work.

\section{References}

1. Bafadhel M, Umar I, Gupta S, et al. The role of CT scanning in multidimensional phenotyping of COPD. Chest. 2011;140(3):634-642.

2. O'Brien C, Guest PJ, Hill SL, Stockley RA. Physiological and radiological characterisation of patients diagnosed with chronic obstructive pulmonary disease in primary care. Thorax. 2000;55(8):635-642.

3. Roche N, Kouassi B, Rabbat A, et al. Yield of sputum microbiological examination in patients hospitalized for exacerbations of chronic obstructive pulmonary disease with purulent sputum. Respiration. 2007;74(1):19-25.

4. Gatheral T, Kumar N, Sansom B, et al. COPD-related bronchiectasis; independent impact on disease course and outcomes. COPD. 2014; 11(6):605-614.

5. Global strategy for the diagnosis, management, and prevention of chronic obstructive pulmonary disease; 2014. Available from: http:// www.goldcopd.org/uploads/users/files/GOLD_Report_2014_Jun11. pdf. Accessed October 10, 2014.

6. Global strategy for the diagnosis, management, and prevention of chronic obstructive pulmonary disease; 2014. Available from: http:// www.goldcopd.org/uploads/users/files/GOLD_Report_2015_Apr2.pdf. Accessed May 11, 2015.

7. Martínez-García MÁ, Soler-Cataluña JJ, Donat Sanz Y, et al. Factors associated with bronchiectasis in patients with COPD. Chest. 2011;140(5):1130-1137.

8. Parr DG, Guest PG, Reynolds JH, et al. Prevalence and impact of bronchiectasis in alpha1-antitrypsin deficiency. American Journal of Respiratory and Critical Care Medicine. 2007;176(12):1215-1221.

9. Patel IS, Vlahos I, Wilkinson TM, et al. Bronchiectasis, exacerbation indices, and inflammation in chronic obstructive pulmonary disease. American Journal of Respiratory and Critical Care Medicine. 2004;170(4):400-407.

10. Garcia-Vidal C, Almagro P, Romaní V, et al. Pseudomonas aeruginosa in patients hospitalised for COPD exacerbation: a prospective study. European Respiratory Journal. 2009;34(5):1072-1078.

11. Fujimoto K, Kitaguchi Y, Kubo K, Honda T. Clinical analysis of chronic obstructive pulmonary disease phenotypes classified using high-resolution computed tomography. Respirology. 2006;11(6): 731-740.
12. Tulek B, Kivrak AS, Ozbek S, et al. Phenotyping of chronic obstructive pulmonary disease suing the modified Bhalla scoring system for high-resolution computed tomography. Can Respir J. 2013;20(2): 91-96.

13. Martínez-García MA, de la Rosa Carrillo D, Soler-Cataluña JJ, et al. Prognostic value of bronchiectasis in patients with moderate-to-severe chronic obstructive pulmonary disease. American Journal of Respiratory and Critical Care Medicine. 2013;187(8):823-831.

14. Gallego M, Pomares X, Espasa M, et al. Pseudomonas aeruginosa isolates in severe chronic obstructive pulmonary disease: characterization and risk factors. BMC Pulmonary Medicine. 2014;14:103.

15. Goeminne PC, Nawrot TS, Ruttens D, et al. Mortality in non-cystic fibrosis bronchiectasis: a prospective cohort analysis. Respiratory Medicine. 2014;108(2):287-296.

16. Lin SH, Ji BC, Shi YM, et al. Comorbid pulmonary disease and risk of community-acquired pneumonia in COPD patients. Int J Tuberc Lung Dis. 2013;17(12):1638-1644.

17. Kim SS, Seo JB, Lee YH, et al. Chronic obstructive pulmonary disease: lobe-based visual assessment of volumetric CT by using standard images - comparison with quantitative $\mathrm{CT}$ and pulmonary function test in the COPD gene study. Radiology. 2013;266(2): 626-635.

18. Moher D, Liberati A, Tetzlaff J, Altman DG; PRISMA Group. Preferred reporting items for systematic reviews and meta-analyses: the PRISMA statement. Int J Surg. 2010;8(5):336-341.

19. Rostom A, Dube C, Cranney A, et al. Celiac Disease. Rockville (MD): Agency for Healthcare Research and Quality (US); 2004 Sep. (Evidence Reports/Technology Assessments, No 104.) Appendix D. Quality Assessment Forms. Available from: http://www.ncbi.nlm.nih. gov/books/NBK35156

20. Sweeting MJ, Sutton AJ, Lambert PC. What to add to nothing? Use and avoidance of continuity corrections in meta-analysis of sparse data. Stat Med. 2004;23(9):1351-1375.

21. Hozo SP, Djulbegovic B, Hozo I. Estimating the mean and variance from the median, range, and the size of a sample. BMC medical research methodology. 2005;5:13.

22. Gon calvesa JR, Pereirab MC, De Cerqueiraa EP, et al. Severe obstructive disease: Similarities and differences between smoker and nonsmoker patients with COPD and/or bronchiectasis. Rev Port Pneumol. 2013;19(1):13-18.

23. Goddard PR, Nicholson EM, Laszlo G, Watt I. Computed tomography in pulmonary emphysema. Clin Radiol. 1982;33:379-387.

24. Bhalla M, Turcios N, Aponte V, et al. Cystic fibrosis: scoring system with thin-section CT. Radiology. 1991;179:783-788.

25. Han MK, Bartholmai B, Liu LX, et al. Clinical significance of radiologic characterizations in COPD. COPD. 2009;6(6):459-467.

26. Kinsella M, Müller NL, Abboud RT, et al. Quantitation of emphysema by computed tomography using a 'density mask' program and correlation with pulmonary function tests. Chest. 1990;97(2): 315-321.

27. Nakano Y, Muro S, Sakai H, et al. Computed tomographic measurements of airway dimensions and emphysema in smokers. Correlation with lung function. American Journal of Respiratory and Critical Care Medicine. 2000;162(3 Pt 1):1102-1108.

28. Miravitlles M, Calle M, Soler-Cataluña JJ. Clinical phenotypes of COPD: identification, definition and implications for guidelines. Arch Bronconeumol. 2012;48(3):86-98.

29. Fuschillo S, De Felice A, Balzano G. Mucosal inflammation in idiopathic bronchiectasis: cellular and molecular mechanisms. Eur Respir J. 2008;31(2):396-406.

30. Barnes PJ. Chronic obstructive pulmonary disease. N Engl J Med. 2000; 343(4):269-280.

31. Whitwell F. A study of the pathology and pathogenesis of bronchiectasis. Thorax. 1952;7(3):213-239.

32. Hogg JC, Chu F, Utokaparch S, et al. The nature of small-airway obstruction in chronic obstructive pulmonary disease. $N$ Engl J Med. 2004;350(26):2645-2653. 
33. Agusti A, Calverley PM, Celli B, et al. Evaluation of COPD Longitudinally to Identify Predictive Surrogate Endpoints (ECLIPSE) investigators. Characterisation of COPD heterogeneity in the ECLIPSE cohort. Respir Res. 2010;11:122.

34. Boucher RC. Relationship of airway epithelial ion transport to chronic bronchitis. Proc Am Thorac Soc. 2004;1(1):66-70.

35. Reid LM. Reduction in bronchial subdivision in bronchiectasis. Thorax. 1950;5(3):233-247.

36. Hansell DM, Wells AU, Rubens MB, Cole PJ. Bronchiectasis: functional significance of areas of decreased attenuation at expiratory CT. Radiology. 1994;193(2):369-374.

37. Novosad SA, Barker AF. Chronic obstructive pulmonary disease and bronchiectasis. Curr Opin Pulm Med. 2013;19(2):133-139.

38. Cole PJ. Inflammation: a two-edged sword the model of bronchiectasis. Eur J Respir Dis Suppl. 1986;147:6-15.

39. Engler K, Mühlemann K, Garzoni C, et al. Colonization with Pseudomonas aeruginosa and antibiotic resistance patterns in COPD patients. Swiss Med Wkly. 2012;142:w13509.
40. Patel IS1, Seemungal TA, Wilks M, et al. Relationship between bacterial colonization and the frequency, character, and severity of COPD exacerbations. Thorax. 2002;57(9):759-764.

41. Groenewegen KH, Wouters EF. Bacterial infections in patients requiring admission for an acute exacerbation of COPD; a 1-year prospective study. Respir Med. 2003;97(7):770-777.

42. Marin A, Monsó E, Garcia-Nuñez M, et al. Variability and effects of bronchial colonization in patients with moderate COPD. Eur Respir J. 2010;35(2):295-302.

43. Almagro P, Salvadó M, Garcia-Vidal C, et al. Pseudomonas aeruginosa and mortality after hospital admission for chronic obstructive pulmonary disease. Respiration. 2012;84(1):36-43.

44. Hurst JR, Elborn JS, De Soyza A. COPD-bronchiectasis overlap syndrome. Eur Respir J. 2015;45(2):310-313.

45. Hill AT, Pasteur M, Cornford C, Welham S, Bilton D. Primary care summary of the British Thoracic Society Guideline on the management of non-cystic fibrosis bronchiectasis. Prim Care Respir J. 2011; 20(2):135-140.
International Journal of COPD

\section{Publish your work in this journal}

The International Journal of COPD is an international, peer-reviewed journal of therapeutics and pharmacology focusing on concise rapid reporting of clinical studies and reviews in COPD. Special focus is given to the pathophysiological processes underlying the disease, intervention programs, patient focused education, and self management protocols.

\section{Dovepress}

This journal is indexed on PubMed Central, MedLine and CAS. The manuscript management system is completely online and includes a very quick and fair peer-review system, which is all easy to use. Visit http://www.dovepress.com/testimonials.php to read real quotes from published authors.

Submit your manuscript here: http://www.dovepress.com/international-journal-of-chronic-obstructive-pulmonary-disease-journal 